\title{
Demos-Ethos: A framework to study the Basque and Icelandic cases through Critical Social Innovation and Applied Ethics
}

\author{
This paper presents a framework informed by two disciplines, Social Innovation \\ and Applied Ethics, to be used in an on-going analysis of territorial democratic \\ systems. The time frame chosen for the case studies is the period before and after \\ the 2008 global crisis. In Iceland the crisis had an economic and political aspect \\ affecting the self-understanding of the territory as a whole. In the Basque \\ Country it also deals with the current peace process to settle down political \\ violence and its causes. In both cases there are deep underlying value issues, but \\ this paper introduces the results obtained in Iceland. While its democratic system \\ has proven to be able to contest the causes of the crisis, there is no definitive \\ evidence that the re-examination process that was opened on 6th October 2008 is \\ resolved yet.
}

Keywords: democracy, regeneration, Iceland, Basque Country, critical social innovation, applied ethics word

\section{Introduction}

In a recent Innovation article, Grimm et al. (2013) argue that more theoretical and empirical work is needed to help social innovation develop into an effective policy tool. Specifically, Europe needs "first to understand what works in delivering economically successful social innovations which facilitate smart, sustainable and inclusive growth". To help achieve this, they provide a conceptualisation of social innovation, but they also emphasise the need for case studies that locate it in specific contexts: either at the macro-level of institutional arrangements, the meso-level of certain policy areas and organisations, or at the micro-level of local community and neighbourhood politics. (Grimm et al. 2013: 437;450)

One of those aspects in which the concept of social innovation appears undertheorized is the ethical one. As of March 2014, a search for "social innovation" and 
"ethics" in the ISI Web of Science retrieved only one article with citations (Hanke and Stark 2009). A new Journal for Responsible Innovation has been just launched, and in its first issue Taebi et al. (2014) argue that an ideal approach to social innovation requires interdisciplinary research that incorporates ethics (the role of values), institutional theory (the role of organisations), and policy literature (the role of stakeholders). After all, crisis hardly could be understood only in economical terms, without a more comprehensive theory about values in society. How is ethics locally applied, put in place? What is the role of culture and local identity in delivering effective social innovations? To answer those questions, other authors see the need for "instruments to further assess the degree to which an ethical identity exists in an organization and how authentic leadership, aligned processes and ethical culture interact to contribute to it" (Verbos et al. 2007: 28).

Grimm et al. also argue (2013: 447) that one of the challenges in the field is to develop new, multi-method approaches to provide that kind of research. In this paper we attempt such an approach, providing a framework to identify ethical aspects in social innovation, and testing it in a specific context, such as the crisis experimented in the last few years in Iceland. In this on-going two-legged research project, we concentrate at the micro-level by carrying out interviews in order to answer questions about the relationship between public morality, social innovation, and democratic change, focusing on different ways of coping with crisis in two democratic systems: the Basque Country and Iceland. Our general aim in this article is to make explicit tacit understandings and common insights around themes such as political innovation at the global and local scales, the meaning of the 2008-11 financial crisis and its impact on democracy, and the influence of technology and social movements in this hypothetical social transformation, the role of different stakeholders insofar to build up macro/meso/micro socio-economic alternatives. We have proceeded with the qualitative 
method and a comparative perspective of the two case studies, by participant observation of the Icelandic context, while connecting it with the Basque one.

What this article does is (1) to present the overall project, or "Basque-Iceland connection", (2) to describe and justify our main research tool (the "Demos-Ethos framework") as a blueprint to be adapted in similar projects and case studies, and (3) to discuss the first results of the Icelandic case study. The article proceeds in this order, and the conclusions summarise its two main contributions. The first one is methodological: the Demos-Ethos framework as a theoretical tool that can be used to interpret fieldwork qualitative data. The second one is empirical: an interpretation of the Icelandic case study in terms of the 5-systems (Calzada 2013a), values, principles, and behaviours identified by the framework. Thus our research integrates critical social innovation and empirical applied ethics in a new interdisciplinary approach whose methodology includes a review of the existing literature on those topics, peer discussion (Calzada and Casado 2013), and semi-structured interviews with selected stakeholders, which gave their informed consent to become participants in this research.

\section{The Basque-Icelandic connection}

This is a qualitative study (as opposed to quantitative surveys or polls) in which hypothesis from applied ethics (as opposed to more abstract ethical theory) and critical social innovation studies (as opposed to an institutional approach) will be tested by means of conversations and interviews with selected people in Iceland, doing participating observation of both societies (our research workplaces are located in the Basque Country, but we both have lived in Iceland for short and longer periods during

1 http://www.igorcalzada.com/2013/09/basque-iceland-connection-september-september-

2013/;

http://cityregions.org/comparative-territorial-connection/empirical-approach/iceland 
2000-02, 2006, and 2013). We aimed to interview three profiles of stakeholders in both societies: academics, politicians and citizens. (See list of anonymous discussants and their profiles in the Annex.)

Despite the historical links between Iceland and the Basque Country (Edvardsson and Rafnsson 2006) dating back to the 16th century, we have not found any published comparative study in our fields about contemporary Iceland and the Basque Country; as Jón the Learned tells in the Spánverjavígin saga, the relationship between Basque whalers and Icelanders reached a tragic peak in 1615, when about 30 of the former were slaughtered in the region of the West Fjords. Yet they are two societies that might benefit from connecting with each other: they are struggling to get out of a crisis that is more than financial, and they need to readjust their governance systems to the changes of the last years.

Located in between France and Spain, the Basque Country is currently living a whole new scenario. After sixty years of violent struggle with the Spanish state, the Basque separatist group ETA announced a permanent cease of fire in 2010-11. The subsequent efforts to put a peace process in place might be understood in a global context of devolutionist city-regions (Brenner 2014: 15; Calzada 2011a) or small nations redefining their relationship to bigger states and the EU. Similar examples could be found in Scotland(Bailes et al. 2013), Catalonia, Oresund (Calzada 2013a), and even Iceland itself. Iceland did apply for membership in 2009 but then suspended its application until a referendum is called. Because Iceland and the Basque Country share some concerns about the fate of their unique local languages and cultures in a global arena), we aim to study whether some of the changes or innovations emerged in Iceland after the "Kreppa" or financial crisis years (2008-2011) could be applicable to the crisis in the Basque Country in the new post-violence scenario (ETA's ceasefire from 2011 on). 
Our aims involve both theoretical and practical dimensions, so we prefer to use the term "connection" to describe our research intervention. This connection not only involves two countries, but also our respective disciplines: applied ethics (Casado 2008) and critical social innovation studies (Calzada 2011b). We think both might benefit from collaboration. Indeed, in recent years there has been a lot of interest both in empirical approaches to ethics, and in the ethics underlying social transformation.

In this article we focus on Iceland, whose system of governance is a rather messy and complicated political arrangement (Bergmann 2013), thereby resembling the situation in other modern democracies (Kristjánsson 2004). Iceland has been described as a "model country" or a "laboratory society", but it was deeply hit by the 2008 financial crisis. Has it recovered? During the subsequent "Kreppa" years we have been hearing about Iceland's "silent revolution". If there has been some democratic innovation or regeneration in Iceland after the crisis, what relationship does it have with ethics? What is its moral core? Different as they are, both situations involve hopes of regeneration of the democratic system, and both raise questions such as: What has been really happening in Iceland? What is the nature of the changes or social innovations that have emerged? Which are the consequences of such a dramatic crisis in the regeneration of the whole democratic system? In what way is it special or different from the Basque case? Those are the main questions guiding this research.

\section{The Demos-Ethos framework: mapping democratic regeneration}

In order to describe the ethics behind democratic change in a given society or territory, we have developed an inventory or questionnaire to guide interviews. It does it by means of a matrix, which combines ethical indicators looked through the main social innovation 5-system framework of a democratic society, as developed by Calzada (2013a). To capture that "moral core", the emerging mores of democratic change, we 
have used a comprehensive account of the main activities associated with ethics, as adapted by Casado (2013).

\section{1. (Empirical) Applied Ethics}

During the last few decades, the methodology of applied ethics has shifted from a predominant use of normative-philosophical analyses to an increasing involvement of empirical methods; this shift is especially visible in medical ethics (Salloch et al. 2012), but it is not restricted to it. For instance, a recent article in Business Ethics (Fuller 2013) reflects on the utility of crisis as a ground in which "moral entrepreneurship" phenomena arise, reconceptualising past damages as new opportunities to assert what really matters. Empirical ethics continues to flourish notwithstanding on-going battles between moral philosophers and social scientists:

\footnotetext{
"On one flank, moral philosophers, well armed with three centuries worth of arguments about the fact-value distinction, target the validity of empirical ethics research and critique what they see as the empirical ethicists' untenable efforts to develop prescriptive conclusions from descriptive evidence. On the opposing flank, social scientists (and others) attack the distinctiveness of empirical ethics research, with criticisms ranging from empirical ethicists' naive appropriation of the complex methodologies and methods developed from within their disciplines, to their apparent ignorance of social scientists' own attempts to account for the ways in which social practices are laden with judgments of moral value." (Dunn et al.
} 2012: 466)

We are interested in this sense of ethics as "fieldwork in familiar places" (Moody-Adams 1997), but our aim is not simply descriptive or ethnographical. As Reidun Førde argues, “empirical ethics implies more than just descriptions and presentation of 'facts.' One criterion for descriptive studies to be included in the term 'empirical ethics' is that the 'findings' in the studies that are dealing with value issues are discussed analytically and normatively" (Førde 2012: 517). In order to provide this analysis on top of the descriptive research itself, we have included in our framework a 
contribution coming from the field of applied ethics. Based on the work of K. O. Apel, the approach we are introducing was initially developed by J. C. Siurana (2008), and provides a comprehensive account of a number of moral phenomena, which we believe are relevant for our purposes. For Siurana, ethics involves at least three kinds of activities, which roughly correspond to the main features of Apel's idea of the moral subject.

- Self-understanding. We engage in this activity or task whenever we identify or clarify the values, goals or goods that give meaning to a given practice.

- Justification. We engage in this activity when we deliberate or dialogue, aiming to some sort of consensus about the principles used to justify a course of action.

- Application. We engage in this activity when we implement policies in a context of moral pluralism, perform moral judgements assigning responsibilities, or otherwise stipulate the right behaviour in a given situation.

Can we describe the way a particular ethics is applied in a territory? How can we identify emerging trends in moral practice? Those questions are notoriously hard to answer as such, so our strategy is to divide ethics into different items that are a little easier to track. In order to measure how well a given moral subject fares in those three tasks, Siurana provides a couple of indicators for each.

\section{Values}

- E) Ends: this indicator tries to capture the self-understanding of the moral subject(s) by looking at the extent they identify the goals or internal goods that give meaning to a given practice, and the factors influencing their choice of those ends. 
- I) Intersubjectivity: this indicator tries to capture the self-understanding of the moral subject in relation to others, by looking at what they think about the subject.

\section{Principles}

- R) Reflection: this indicator tries to capture to what extent the subject(s) bases their decisions in a dialogue or deliberation in which the right (minimal ethics) and the good (maximal ethics) are considered.

- C) Consensus: this indicator tries to capture to what extent the subject's decisions would have been taken by consent in an ideal community of communication, in which all stakeholders are present in a dialogue on equal grounds.

\section{Behaviours}

- PC) Post-Conventionality: this indicator tries to capture to what extent the subject(s) engage in behaviours that all stakeholders could agree to, irrespectively of their own conception of the good.

- CR) Co-Responsability: this indicator tries to capture to what extent the subject(s) assume a share of responsibility for the consequences of collective behaviour.

Concerning values, this approach considers the ends or internal goods (E indicator) not enough to define a moral identity; identities are social, so we need to have identity somehow recognised by others (I indicator). As for principles, we understand moral norms as justified by deliberation and dialogue (and that is what the $\mathrm{R}$ and $\mathrm{C}$ indicators provide). As for identifying ethical behaviour, in liberal societies we have to take into account the fact of reasonable pluralism (this is what is embodied by PC 
indicator); in such societies ethics is not a job for experts and it cannot be simply applied top-down (and that is why participation and the CR indicator are required).

Our questionnaire (see Annex 1) includes questions that try to elicit answers concerning all those indicators, which we code as E, I, R, D, C, PC, and CR.

\section{2. (Critical) Social Innovation}

Grimm et al. argue that Social Innovation discourses see in social challenges opportunities to make societies more sustainable and cohesive through inclusive practices, coproduction and proactive grassroots initiatives. Nevertheless, and following the premises that Morgan (2013) and Moulaert (2013) founded, what is required is a critical review of this discourse, applying empirical research such as the one we are presenting in this project. The paradigm suggested by Calzada in recent publications is the one called Critical Social Innovation in line with what Moulaert (2003) expressed provocatively:

\footnotetext{
"It is ironic, therefore, despite their significantly higher innovative content, that these initiatives have not gained the academic and policy attention they deserve to compared with the more spectacular, although not necessarily more significant, strategies of urban development through large-scale top-down renovation megaprojects”. (Moulaert, Rodriguez \& Swyngedow 2003: 97)
}

Critical Social Innovation aims to follow that call to attention while being conscious of the two main strategic societal challenges in the EU: the economic and the political. The economic challenge in Social Innovation is how to deconstruct the nature and logic of neoliberalism (Brenner 2014; Harvey 2005). The political challenge implies a shift from efforts to recovering citizens' trust in conventional politics towards regional-based European polycentric collaborative dynamics and initiatives, acknowledging the need of a political reconfiguration of the Nation-State-wise obsolete structures (Ohmae 1995). 
Indeed, Iceland is and has been a good example of a society overcoming the negative effects of the recession and the crisis. As Einarsson argued, as a smaller state Iceland "is more likely than other states to strive for flexibility and to develop a strong ethical ideology which is conducive to the promotion of greater co-operation among the nations of the world" (Griffiths and Magnússon 2004: 5). Following work by Thorhallsson (2012), Kvalnes and Nordal (2013), Bergman (2013), and Conrad (2013), among other authors who have studied the Icelandic case from Autumn 2008 to the present, we seek to diagnose the characterising features of small states like Iceland when facing the two aforementioned challenges.

Our main hypothesis is that Iceland and the Basque Country are two different territories, which are struggling towards a new balance, and democratic regeneration. According to Moulaert (2013), Morgan (2013) and Mulgan (2013), territories and societies should take into account their own features, which are combined systemically in a unique way. Nevertheless, in the same direction of the critique of Grimm et al. ("Social Innovation has become highly popular among policy-makers but its meaning continues to be ambiguous and vague"), Calzada suggests ${ }^{2}$ how this new paradigm of Critical Social Innovation could be integrated in an open prospective 2020 EU horizon scenario (European Commission 2012) with Iceland as a regenerated small state and the Basque Country as a nation/city-region.

The Demos-Ethos diagnosis aims to apply to two different territories an updated version of the Social Innovation paradigm considering not only the causes and the lessons learnt from the 2008 financial recession and crisis, but also the different ways to transform the political context. In our fieldwork, the Iceland crisis is often described as 
a result of the neoliberal paradigm. Although we think it is more appropriate to use the term neoclassic economic orthodoxy rather than simply neoliberalism (Keith et al. 2014: 284, "the neoliberal paradigm is grounded in the assumptions of neoclassic economics"), our first research target is the moral core of the crisis, not its economic consequences. For that purpose, we look into the social processes and the way actors define them, using the six ethical indicators.

Recently, Peck (2013: 153) has highlighted that "simple invocations of neoliberalism as an all-purpose, omnibus explanation for the contemporary condition can never be enough". The social (and financial) ethos is not the same in Iceland and in the Basque Country; there are interesting differences in the ways both territories are dealing with their respective crisis. By exploring those differences, Critical Social Innovation could offer a democratic pathway alternative to the "ideologically driven neo-liberal free market policy" that according to Grimm et al (2013: 450) has failed to "deliver social cohesion and equal life chances for all".

In addition to deconstructing neoclassic economic orthodoxy among the two case studies by scanning the social reality as the agents refer to it, we have a second purpose related to democratic regeneration: to show the way the political system has been regenerated by a different range of factors which our framework attempts to capture. We aim to discover how socially constructed processes take place in the territory. Even though we are conscious that we are comparing a small state such as Iceland with a work-in-progress nation or city-region such as the Basque Country, our hypothesis is that both are small territories with hypothetical socially innovative processes that make a difference on their internal and external development. In contrast with the fixed and normatively bigger Nation-States (Einarsson 2004), we think that smaller territories deal much better with Social Innovation. Our aim is to bring to light the structural tensions and contradictions underlying the economic and social disorders, 
identifying the historical continuities in which present crises can be understood (Streeck 2011: 28). Therefore, our attempt is to set up a methodological tool able to measure qualitatively those phenomena from a critical standpoint, and thus comparatively show how these processes have happened in the two case studies.

After performing a review of publications concerning the ethical factors as well as the Social Innovation processes in the Icelandic and Basque context, the fieldwork has allowed us to engage in Action Research in order to test the Demos-Ethos framework, which begins by separating the analysis in two dimensions:

- $\quad$ Scales (Herod 2011): Critical Social Innovation can be studied as processes (Moulaert; Morgan; Mulgan; Grimm et al.) happening in territorial contexts. In the same way as argued by Grimm et al., we see processes occur in three different and supplementary territorial scales: Macro, Meso, and Micro (Calzada et al. 2013).

- Systems: as Swyngedouw suggested, today the social problematic addressed through Social Innovation has become much more complex due to the deepening mutually reinforcing socioeconomic, socio-political and socio-ecological crises (Moulaert et al. 2013). This is, in fact, a systemic prescription for any ethnographic observation.

The research aspect in which we focus on from the critical social innovation perspective (as part of a wider research project) ${ }^{3}$ is the Macro territorial level ${ }^{4}$, which will be diagnosed in separated but interlinked 5-systems framework..These 5 systems aim to provide us with a picture of how a given territory behaves in relation to the social

\section{3 http://www.cityregions.org.}

4 The interviews allow us to scan the micro level as a way to connect fthe micro and the macro levels. 
innovation processes occurring into it. Considering Iceland and the Basque Country as city-regions (Morgan 2013), their development can go in several directions as a consequence of the implemented policies. The following is an explanation of the 5system framework (Calzada 2013a) and the factors that are included in each system.

City-regions are defined by explicit or implicit strategies. From the Critical Social Innovation perspective (Calzada 2013b) these strategies can be designed in one direction or another and they have direct systemic effects on: (1) the physical infrastructures set and the resilient distribution of the scarce material resources among citizens: URBS, the Urban System; (2) the level usage of these resources to satisfy the citizens' need for physical, digital and social connectivity: CYBER, the Relational System; (3) the active consideration of the diverse and complex civilian fabric and their mechanisms to regenerate a transition-based regional political economy: CIVITAS, the Socio-Cultural System; (4) the role of politics in its global and local scales, when it refers to stakeholders' complex participative interaction to reframe the governance model: POLIS, the Socio-Political System. (5) To sum up, all these strategies affect the DEMOS, the Democratic System of the city-region as a whole. Therefore, the framework consists of the following 5 systems.

\section{URBS: Urban System}

City-region analysis is always focused on this system, which is technical and physical. The Smart City (Hollands 2008) standard pattern is just concerned with the URBS and the digital connectivity in CYBER. It looks at the tangible and visible part of the territorial space without considering the relational aspects of this technical system. It contains three factors for analysis:

1.1. Human Geography, or sociodemographic factors. 
1.2. Climate Change, Energy, Sustainability and Resilience, or technical factors.

1.3. Urban \& Rural and Hub \& Spoke Linkage, or morphological and mobility factors (Harrison 2007).

Some of the questions affecting this system are: What are the human geography critical factors for the socially innovative understanding of the city-region? Are the infrastructures well designed for the covered territorial scale and human needs?

\section{CYBER: Relational System}

This system focuses on the spaces of flows and spaces of places (Castells 1996). The good or bad usage of URBS can be understood as the physical CYBER. Three factors are:

2.1.- Physical Connectivity, or usage of the land/users relationship factors.

2.2.- Digital Connectivity, or interaction enabling factors (Hollands 2008).

2.3.- Social Connectivity, or Social Capital factors

Some of the questions: Is the city-region well designed from the shared mobility perspective? What is the role of technology in the urban-human everyday life (Robinson 2006)? What are the challenges for Social Connectivity in order to increase the Communitarian Social Capital rate (Putnam 2001)?

\section{CIVITAS: Socio-Cultural System}

This system treats the citizenship (Keith et al. 2014) configuration in the given city-region. Once we have traced and identified the "hard" side of the city-region and how this is used dynamically, with CIVITAS we approach the "soft" part that is 
sometimes ignored by classical urbanism. It contains three factors for analysis:

3.1.- Inmigration, or ethnic diversity and integration factors.

3.2.- Entrepreneurship, or socio-economic challenged factors.

3.3.- Local Communitarian Development, or local grassroots and bottom-up factors.

Questions include: How is the city-region considering immigration and diversity, local communities and grassroots, social entrepreneurship, education and talent?

\section{POLIS: Socio-Political System}

Finally, this system analyses the power relations and dynamics (Innerarity 2013). It contains three factors for analysis:

4.1.- Globalization, or threats and opportunities factors.

4.2.- Governance, or factors enabling dialogue between stakeholders.

4.3.- Participation, or preconditions, mobilisation and participation process factors.

Some of the questions are: How can we represent the city-region taking into account the global and local sphere and the translocal migration dynamics? What is the role of the participation? Finally, what are the constitutive elements of governance and the power relations between stakeholders?

\section{DEMOS: Democratic System}

To sum up, we obtain the systemic sum of the previous four systems in an 
interdependent and permanent balance. This we cross with the six ethical indicators (grouped in values, principles, and behaviours) to complete the Demos-Ethos framework, which we used to guide and analyse the collection of fieldwork data.

\section{3.- The Demos-Ethos matrix: Action Research methodology}

As explained in the novel Smilla's Sense of Snow, "There is one way to understand another culture. Living it. Move into it, ask to be tolerated as a guest, learn the language. At some point understanding may come.” (Høeg 1993: 193) Our main concern with ethical aspects in social innovation brings us to a comparative fieldwork with two components, Ethos and Demos, united by a methodology based on Action Research. On the one hand, we attempt to capture the Demos component via a systemic analysis, summarising in an interdependent sum the whole 5-System framework. On the other hand, the Ethos component is brought about by an ethnographic analysis via interviews. The resulting tool is the Demos-Ethos that we have been using to organise the insights that we present in the next section.

Despite the differences in fieldwork methodologies, the action research technique is based on the idea that researchers "ought to stay in the field long enough for his/her presence to be considered more or less 'natural' by the permanent residents, the discussants, although he/she will always to some extent remain a stranger" (Eriksen 2010: 27). The fieldwork in Iceland has been carried out mainly with three main profiles of discussants: academics, politicians and citizens. Action research methodology is a resourceful way to attempt to understand the dynamics of emerging topics such as these, in which unprecedented facts are to be studied by following-up news, reviewing policy papers and reports, reading academic papers and at the same time gathering qualitative data via interviews; the goal is to remain up to day and show new results as they emerge in this on-going research process. As for data collection, it was done on a daily basis by 
means of interviews, and it was not difficult to talk about the selected topics.

Finally, we present some results gathered in the first case study. When quoting some of the discussants' transcriptions we keep their anonymity, referring to them by the number in Annex 2. Because it involved political opinions and other data whose disclosure might be potentially problematic, participation in the study was strictly voluntary and confidential. We asked the participation of active members of the Icelandic society and informed consent was sought prior to data collection. We spoke with them for one to two hours, using several versions of the questionnaire in Annex 1, and those conversations were recorded in audio and coded in a simplified transcription. The extracts appearing in the quotations are entirely anonymous.

\section{4.- Icelandic case study: results and discussion}

Our research provides some hypothesis about what is going on in Iceland; let us now unpack those insights one by one, using the different social innovation systems and ethical indicators in our framework.

\section{URBS}

According to the Financial Times (09/27/2013), Iceland seems to enjoy “abundant natural resources that even the most over exuberant financiers and politicians could not damage too much". This somewhat stereotypical image is supported by the fact that, after all, the crisis in Iceland has not lasted too long, and recovery seems to be under way. Traditional and new Icelandic industries such as fishing and tourism are now instrumental in activating the economy at the micro-level. This brings us back to the pre-2008 situation, in which for more than three decades the greatest political dispute in Iceland had to do with the control of the fishing quota (Bergmann 2013: 11).

But not everything is business as usual. According to Bergman (2013), after the 
process experimented in Iceland became highly politicised, a "new critical order" emerged from the crisis, contesting most initiatives for what might constitute a recovery. In another recent publication, ${ }^{5}$ Thorvalgur Gylfasson blamed the politicians: “in spite of clear popular support, Iceland's new crowd-sourced constitution was recently killed by politicians". Discussant \#4 mentioned that political parties found it difficult to agree on the provision concerning ownership of natural resources in the constitutional draft. He doubted that neoliberalism could be the main cause of the economic collapse, and rather pointed to Icelandic individualism as the source of this attitude.

\section{CYBER}

Social networks are widely used in Iceland. They can be understood as "liquid" artefacts (as opposed to "solid", official narratives) that help citizens to engage in political storytelling ("mythopoetic" practices that help citizens understand themselves and their social world) in a collaborative fashion. The 2008 collapse sparked the socalled "kitchenware revolution" during 2009: a grassroots civic movement that vented its anger through public contestation began an unprecedented socially innovative process. Civil society became mobilised, a change of government was provoked, and democratic regeneration benefited from the smallness in social systemic changes.

The resulting constitutional reform process has been noted by scholars at the Comparative Constitutions Project at Chicago University. After analysing the draft, they claimed, "this constitution-making process has been tremendously innovative and participative" (Bergmann 2013: 9).

5 http://www.opendemocracy.net/can-europe-make-it/thorvaldurgylfason/democracy-on-ice-post-mortem-of-icelandic-constitution 


\section{CIVITAS}

Despite overwhelming support for democratic regeneration and constitutional reform, repeatedly the process has been hijacked by political party infighting. Icelanders have proved with their "pots and pans revolution" that civic society is awake, and perhaps this mobilisation played an emotional healing role for society after the collapse. If the reform process drags on for too long (as it did already), the constitutional moment might pass while the economy continues to recover, and as a result democratic regeneration will not bring about a formal constitutional reform. Nevertheless, as Kvalnes and Nordal (2013) underline, there is a general feeling that the collapse happened at a time when "values such as honesty and prudence had been replaced by greed and selfinterest; the successful business people had gained at the cost of the public".

\section{POLIS}

Drafting a new constitution was a very valuable and complex innovative process. Despite strong popular support, the effort to put a new constitution in place failed. Several discussants mentioned that this failure was a mistake due to lack of deliberation and trust. The liquid artefacts enabled the awakening of the civic society, but they were not hard enough to fulfil the constitutional reform task. Two reasons care identified by Gylfason (2013): electoral reform and the unresolved socio-economic issue of the national ownership of natural resources. Gylfasson holds as responsible "the political allies of special interest groups such as fishing vessel owners whom the politicians had turned into a state within the state through gratis allocation of valuable fishing licenses".

\section{DEMOS}

Iceland is in a state of on-going re-examination. The civic and technical challenges of drafting a new constitution were met, but it did not complete a full democratic regeneration. The dispute over ownership of natural resources can be read as a process 
in which the URBS system causes direct effects on POLIS; as a result, it provoked an outstanding civilian mobilisation in the CIVITAS supported and amplified by the CYBER. To sum up, a political system based on conventional party politics is not being able to regenerate the DEMOS. The emergency in October $6^{\text {th }}, 2008$, started a regeneration process but it did not last enough, even if it brought about some positive collateral effects on the democratic system. As Bergman $(2014: 1 ; 18)$ notes, since achieving independence in 1944 Iceland has struggled to find its place in the world, but it "remains an unfinished project, and in that sense the Icelandic sovereignty project is still a work in progress."

\section{ETHOS}

Several discussants described the crisis as affecting Icelandic identity itself, not only the economy or the political system. Iceland took a significant economic toll following the recession starting in late 2008; unemployment rose sharply, with personal and business bankruptcies too. However, the suicide rate has been relatively stable in Iceland, and not affected by the current economic crisis (Oskarsson and Bjarnadóttir 2013). But despite the 2008 collapse, Iceland has shown that less economic activity may contribute to a slower pace of life and strengthen social capital by providing more opportunities for civic participation and social networking. Indeed, some Icelanders did see the crisis as a "blessing in disguise for a nation that had lost its basic values to greed and narcissism", offering a chance to "recover to become a more democratic, human and fair society" (Ólafsdóttir 2009).

Some developments in the field of applied ethics suggest that the "living code" (moral practice as experienced in everyday deliberation and choice, as opposed to a merely written code of ethics) of a society could provide a sort of protection "from some of the negative effects of organisational crises" (Verbos et al. 2007: 27). Were that 
the case in Iceland, some traces of that "living code" should be visible in our fieldwork results.

\section{VALUES}

Paradoxically, Icelanders seem to value themselves because they have a keen sense of their vulnerability as a society: "small societies are culturally vulnerable, specially now, we are getting much more information from abroad in a very short time" (discussant \#1). Discussant \#3 explained this feeling thus: "we are inside the EU market but we don't enjoy its institutional protections" and feel "quite defenceless against the banks". Other discussant (\#4) remembered that in the first months after the collapse the society went "back to basics", to the older values of austerity and restraint, "doing again things like knitting".

Icelanders value very much their culture and the social resilience it affords: "our cultural roots were so strong that we could survive 500 very difficult years" (\#1). Another discussant (\#6) added that "Iceland is a literary culture first and foremost, literature is the strongest source of identity here and the Icelandic language has a completely different status than in other countries". Cohesion is a value but does not come without its costs: according to one discussant (\#5), Iceland is cohesive but inefficient, and Icelanders are "highly aware that people are quite careless in most of their dealings".

\section{PRINCIPLES}

There is a principle of self-interest very actively at work: "we are very selfcentred", said discussant \#2, and more than ever Iceland now does pay attention to its own interests. At the same time, there seems to be a common agreement that everyone is important. In a place like Iceland, no social capital can go to waste, because "we are too few, and the society is complex, to run it well, you have to have many good people 
placed in many different positions" (\#1). Another important principle is adaptivity and optimism in the face of uncertainty. "You have to be adaptive, resilient and optimistic", said discussant \#2, because "being opportunistic was crucial for survival", and nothing is ever final. (There is even an Icelandic saying for that, Petta reddast, "it will turn out well at the end".)

Discussant \#2 insisted in that "to be able to function you have to believe, to have trust", but another discussant (\#4) saw that too much trust could be problematic, since constitutional reform failed because "failure of prevision prevented deliberation to take place". We have already mentioned the on-going re-examination of society as a common feature, one that has not disappeared, and a discussant expressed his hope that the new constitution project will be "a new base for public discussion in Iceland, which will materialise in some form in the coming years" (\#3).

\section{BEHAVIOURS}

The main behaviour in what respects the way out of the crisis is some kind of back to basics attitude, "a mixture of social action and economic downsizing" (\#3) with tourism and fishing as main engines. Discussant \#2 saw the best solution in getting "different groups working together as well as possible", because (as he put it) "Iceland is the country with most Facebook accounts per capita in the world" and "a highly interconnected nepotistic society" in which the internet is "essential in our politics". In Iceland, it seems, "it is better to be a doer than a thinker", and as a result they suffer from some kind of "attention-deficit hyper activism" (\#5); being accepted as a member of Icelandic society is "as hard as becoming a member of a small family" (\#6).

This permanent improvisation leads to mild forms of responsibility. But even if there is some extent of finger pointing and relatively less impunity, Icelanders say, "we vent our anger non-violently" (\#2). This discussant stressed the personal character of 
Icelandic politics: "political ideology doesn't count” in such a small but resilient cityregion (Brenner 2014), "we have always had a quite personal and antagonistic politics" (\#2). Not surprisingly, another discussant (\#5) complained that "Iceland does not have a good forum for public reason, media are lousy". The lack of a real forum for serious public debate is not caused by social stratification, because "here you can present your ideas, you can always express your opinion, you needn't a background of education or standing". What is lacking are "deliberation skills" (\#5).

\section{Conclusions}

On October the $6^{\text {th }}, 2008$, the financial crisis shook all of Iceland and this small population in the middle of the Atlantic seemed to face one of its most critically historical steps ever. Meanwhile the world looked at it in astonishment, although some had anticipated that something like that was bound to happen as a consequence of the policies that Iceland had been adopting during the previous years, like other EU countries that suffered the same crisis. The country entered into an on-going reexamination process as a result of the shock suffered. Here are some conclusions after applying the Demos-Ethos framework to the Icelandic post-crisis context seen from the Basque perspective.

1.- The democratic regeneration started but is not over yet. After the "kitchenware revolution" exploded, angry citizens revolted in a pacific way so as to bring about a new political order. However, interviewees agreed that although the constitutional reform was a technically and socially innovative democratic regeneration process, Iceland as a whole was not able to fulfil it.

2.- Sometimes crises are able to show us systemic contradictions that otherwise we would not able to notice in times of affluence. For two decades in Iceland, neoclassic economic orthodoxy experimented with a small-sized territory with unique 
natural resources, attempting to set up a new version of Nordic neoliberalism. The "2008 crash" reflected the social costs of living in a bubble that can explode from one day to another. The financial collapse taught Icelanders that in democratic systems there are limits that are best not to exceed.

3.- The socially innovative process that aimed at a democratic regeneration in Iceland proved that no matter how small the city-region, a resilient civilian response after the collapse was the best antidote to the neoliberal practices and its results. The Icelandic civil society was alive and awake enough to respond to the misalignments that had made Iceland so vulnerable to the crisis.

4.- At the present moment, Iceland faces two challenges to survive in the global world, in relation to crises management and further democratic regenerations: on the one hand, to reinforce its sovereign political economy as a small state coping with cityregionalist challenges, and, on the other hand, to make its own decisions while being connected with global and translocal networks. This conclusion could be shared with the Basque Country in terms of openness and the request for global interdependency.

5.- Finally, the conclusion after analysing the Icelandic case from the perspective of both Critical Social Innovation and Applied Ethics perspective is that its democracy is a living organism whose balance is delicate but resilient; once its metabolism is damaged, it can react as an adaptive complex system (Heylighen 2013), self-regulating itself.

This final point opens up a research line for further questions in relation both to Iceland and the Basque Country. Indeed, how can small territories such as Iceland (a city-region shaped as small state) and the Basque Country (a work-in-progress cityregion) connect with the rest of the international sphere? Will the need for new forms of interdependence (Nicolaidis 2013) bring about a commitment to avoid neoliberal global 
hazards, while setting up an alternative regional democratic regeneration?

\section{Acknowledgments}

We are grateful to our hosts, Mikael Karlsson and Barbara Nelson, the Philosophy Department at the University of Iceland, the anonymous discussants, the reviewers and editors of this journal, and George Fourlas for helpful comments and suggestions. We also thank Ikerbasque - Basque Foundation for Science and the University of the Basque Country for research funding.

\section{References}

Bailes, A.J.K., B. Thorhallsson, and R. L. Johnstone. 2013. "Scotland as an Independent Small State: Where would it seek shelter?" Icelandic Review of Politics and Administration 9(1):1-20.

Bergman, E. 2013. "Reconstituting Iceland (constitutional reform caught in a new critical order in the wake of crisis)." Working paper presented in the workshop Crowd-pleasers or key janglers? The impact of drops in political legitimacy on democratic reform and their consequences. Leiden University, January 24-25, 2013.

Bergman, E. 2014. "Iceland: A postimperial sovereignty project." Cooperation and Conflict online version: 1-22.

Brenner, N. 2014. Implosions / Explosions: Towards a Study of Planetary Urbanization. Berlin: Jovis.

Calzada, I. 2011a. Towards the Basque City? Comparative Territorial Benchmarking from Social Innovation: Dublin (Ireland) \& Portland (Oregon). Bilbao: Innobasque-Basque Innovation Agency.

Calzada, I. 2011b. ¿Hacia una Ciudad Vasca? Aproximación desde la Innovación Social. Vitoria-Gasteiz: Servicio Central de Publicaciones del Gobierno Vasco.

Calzada, I. 2013a. "The Future of City-Regions $<>$ Comparative Territorial Benchmarking: Basque \& Oresund." In Conference Proceedings of the Regional Studies Association (RSA) Winter Conference November 2013, edited by RSA, 19-25. London: RSA.

Calzada, I. 2013b. "Critical Social Innovation in the Smart City era for a City-Regional European Horizon 2020.” Journal of Public Policies \& Territory P3T 2(6): 1-20. 
Calzada, I. and A. Casado. 2013. "Basque \& Iceland Connection." Paper given at the Philosophy Department, University of Iceland, Reykjavík, September $27^{\text {th }}$.

Calzada, I., A. Chautón, and D. Di Sienna. 2013. \#MacroMesoMicro: Systemic

Territory Framework from the perspective of Social Innovation. https://www.academia.edu/5299165/_MacroMesoMicro_Systemic_Territory_ Framework_from_the_perspective_of_Social_Innovation

Casado, A. 2008. Bioética para legos. Madrid / México: CSIC / Plaza y Valdés.

Castells, M. 1996. The Rise of the Network Society. Oxford: Blackwell.

Conrad, M. 2013. “A Small-States Perspective on the European Citizens' Initiative.” Icelandic Review of Politics and Administration 9(2): 301-322.

Dunn, M., M. Sheehan, M. Parker, and T. Hope. 2012. “Towards methodological innovation in empirical ethics research." Cambridge Quarterly of Healthcare Ethics 21(4): 466-480.

Edvardsson, R., and M. Rafnsson. 2006. Basque Whaling Around Iceland: Archeological Investigation in Strákatangi, Steingrímsfjörður. Bolungarvík: Náttúrustofa Vestfjarða, \& Hólmavík: Strandagaldur.

Eriksen, T. H. 2010. Small Places, Large Issues. An Introduction to Social and Cultural Anthropology, $2^{\text {nd }}$ ed. London: PlutoPress.

European Commission. 2012. Strengthening Social Innovation in Europe. Brussels: European Union.

Førde, R. 2012. “How Can Empirical Ethics Improve Medical Practice?” Cambridge Quarterly of Healthcare Ethics 21(4): 517-526.

Grimm, R., C. Fox, S. Baines, and K. Albertson. 2013. "Social innovation, an answer to contemporary societal challenges? Locating the concept in theory and practice." Innovation: The European Journal of Social Science Research 26(4): 436-455.

Gylfasson, T. 2013. Democracy on ice: a post-mortem of the Icelandic constitution, at Open Democracy. http://www.opendemocracy.net/can-europe-makeit/thorvaldur-gylfason/democracy-on-ice-post-mortem-of-icelandicconstitution.

Hanke, T., and W. Stark. 2009. "Strategy Development: Conceptual Framework on Corporate Social Responsibility." Journal of Business Ethics 85: 507-516.

Harrison, J. 2007. "From competitive regions to competitive city-regions: A new orthodoxy, but some old mistakes." Journal of Economic Geography 7(3): 311332.

Harvey, D. 2005. A Brief History of Neoliberalism. Oxford: Oxford University Press. 
Herod, A. 2011. Scale. London: Routledge.

Heylighen, F. 2013. "Self-organization in Communicating Groups: the emergence of coordination, shared references and collective intelligence." In Complexity perspectives on language, communication, and society, edited by A. MassipBonet and A. Bastardas-Boada, 117-150. Berlin: Springer.

Høeg, P. 1993. Smilla's Sense of Snow. New York: Bantam Doubleday Dell.

Hollands, R. G. 2008. "Will the real smart city please stand up?" City: analysis of urban trends, culture, theory, policy, action 12(3): 303-320.

Innerarity, D. 2013. The Democracy of Knowledge. London: Bloomsbury.

Keith, M., S. Lash, J. Arnoldi, and T. Rooker. 2014. China Constructing Capitalism. London: Routledge.

Kristjánsson, K. 2004. "Iceland: Searching for Democracy along Three Dimensions of Citizen Control." Scandinavian Political Studies 27(2): 153-174.

Kvalnes, O. and S. Nordal. 2013. "Moral neutralization in the Icelandic financial crisis." Working paper.

Griffiths, G., and G. Magnússon. 2004. Small States and European Economic Integration. Reykjavík: Centre for Small State Studies, Institute of International Affairs, University of Iceland.

Morgan, K. 2013. "The Rise of Metropolitics: Urban Governance in the Age of the CityRegion." In Governing Urban Economies: Innovation and Inclusion in Canadian City-Regions, edited by N. Bradford and A. Bramwell. Toronto: University of Toronto Press.

Moody-Adams, M. M. 1997. Fieldwork in familiar places: morality, culture, and philosophy, Cambridge (Mass.): Harvard University Press.

Moulaert, F., D. MacCallum, A. Mehmood, and A. Hamdouch. 2013. International Handbook of Social Innovation. Social Innovation: Collective Action, Social Learning and Transdisciplinary Research. Cheltenham: Edward Elgar.

Moulaert, F. 2009. "Social Innovation: Institutionally Embedded, Territorially.” In Social Innovation and Territorial Development, edited by D. MacCallum, F. Moulaert, K. Hiller, and V. Haddock, 11-24. Franaham: Ashgate.

Mulgan, G., and R. Puttick, R. 2013. Making evidence useful: the case for new institutions. London: NESTA.

Nicolaidis, K. 2013. "European Demoicracy and Its Crisis", Journal of Common Market Studies, Volumen 51. Number 2. pp. 351-369. 
Ohmae, K. 1995. The end of the nation state: the rise of regional economies. New York: Simon and Schuster.

Peck, J. 2013. “Explaining (with) Neoliberalism.” Territory, Politics, Governance 1(2): 132-157.

Putnam, R. 2001. Bowling Alone: The Collapse and Revival of American Community. New York: Simon and Schuster.

Robinson, J. 2006. Ordinary Cities: Between Modernity and Development. London: Routledge.

Salloch, S., J. Schildmann, and J. Vollmann. 2012. "Empirical research in medical ethics: How conceptual accounts on normative-empirical collaboration may improve research practice." BMC Medical Ethics 13:5.

Siurana, J. C. 2009. La sociedad ética. Indicadores para evaluar éticamente una sociedad. Barcelona: Proteus.

Streeck, W. 2011. “The Crises of Democratic Capitalism.” New Left Review 71: 5-29.

Taebi, B., A. Correlje, E. Cuppen, M. Dignum, and U. Pesch. 2014. "Responsible Innovation as an Endorsement of Public Values: The Need for Interdisciplinary Research." Journal of Responsible Innovation 1(1).

Thorhallsson, B. 2012. "The Icelandic Economic Collapse: How to overcome constraints associated with smallness?” European Political Science 12: 320-332.

Verbos, A., J. Gerard, P. Forshey, C. Harding, and J. Miller. 2007. "The Positive Ethical Organization: Enacting a Living Code of Ethics and Ethical Organizational Identity." Journal of Business Ethics 76: 17-33. 


\section{Annex}

\section{Questionnaire}

- VALUES

- E: What are the main goals or shared ends in your workplace? What are the goods that give meaning to your life? What is the best thing about the place you live in? What is there in your profession for you?

○ I: How do you empathise or connect with other people around you? What kind of self-image you get from people in other places in the world? Is there something about your culture that might be valuable to others? What is special or distinctive about your profession/organisation?

\section{- PRINCIPLES}

- R: What kind of spaces, interactions or relationships make it possible for you to engage in dialogue with yourself and with others who might not be present? Be it about justice or happiness, how is reflection incorporated in your everyday life? Is there any distinction between personal and collective ends, between the private and the public spheres? Is there any contribution that your profession has done in terms of authenticity and autonomy?

○ $\mathrm{C}$ : How is collective deliberation and choice performed in the place you live in? What are the norms that attract more consensus when debated? How consensual or convivial is decision making in the networks you participate in? Is polarisation a feature of your organisation?

\section{- BEHAVIOURS}

○ PC: How diverse is your workplace, the professional networks you participate in? To what extent can your society accommodate different 
cultures? Is there any politics of recognition of cultural difference in the place you live? Are there any rights important for you irrespectively of your own conception of the good?

- CR: Is your organisation sustainable? Are people accountable for what they do in those networks? Despite cultural differences, does everyone assume responsibility for the collective behaviour? Does everyone contribute a fair share to the common good?

\section{Discussant list}

- $\quad$ Discussant \#1 > Bifrost University

- Discussant \#2 > Reykjavik City Hall

- Discussant \#3 > Bifrost University

- Discussant \#4 > University of Iceland and Constitutional Reform Board

- Discussant \#5 > University of Iceland

- Discussant \#6 > University of Iceland

- $\quad$ Discussant \#7 > University of Iceland

- $\quad$ Discussant \#8 > National Library

- $\quad$ Discussant \#9 > University of Iceland

- Discussant \#10 > Parliament of Iceland 